\title{
Absenteeism among survivors of the atomic bombing of Hiroshima
}

\author{
J. WISTER MEIGS ${ }^{1}$, WILLIAM J. BLOT ${ }^{2}$, S. INOUE ${ }^{3}$, and \\ CAMILLA R. MEIGS ${ }^{1}$ \\ School of Medicine, Yale University, New Haven, Connecticut ${ }^{1}$, Johns Hopkins University \\ School of Hygiene and Public Health, Baltimore, Maryland ${ }^{2}$, and Atomic Bomb Casualty \\ Commission, Hiroshima, Japan ${ }^{3}$
}

\begin{abstract}
Meigs, J. Wister, Blot, W. J., Inoue, S., and Meigs, Camilla R. (1975). British Journal of Industrial Medicine, 32, 193-202. Absenteeism among survivors of the atomic bombing of Hiroshima. Atomic bomb survivors who worked at the Atomic Bomb Casualty Commission in Hiroshima during the years 1968-71 and held handbooks identifying them as survivors took significantly more days of both annual leave and sick leave than did matched and paired control subjects. These differences in leave-taking patterns are considered to be due to behavioural causes as they could not be attributed to radiation dose-response effects.
\end{abstract}

Many people believe that atomic bomb (A-bomb) survivors who had no evidence of radiation injury at the time of the bombings on 6 and 9 August 1945, or within the next few months, could nevertheless be expected to have excess illness. Absences from work are often indicators of illness, and these were studied at the Atomic Bomb Casualty Commission (ABCC) to learn whether A-bomb survivors working at the headquarters of the Commission in Hiroshima had experienced absentee rates that differed from those of matched controls; and whether these differences, if any, were dependent on the dose of radiation. Many interesting aspects of absenteeism were purposely not covered in detail in order to permit a study design that appeared to have the greatest chance of answering the question whether or not A-bomb survivors had significantly more absenteeism than suitably chosen controls.

\section{Reported chronic effects of atomic bombing at Hiroshima and Nagasaki}

Matsumoto (1969) described the major events related to the atomic bombs that have occurred in Hiroshima and Nagasaki since 1945 . He noted the extensive publicity given to these events, and pointed out that the cumulative effects of such publicity might be expected to perpetuate and intensify the air of anxiety among the survivors'. The local media continue to report morbidity or mortality of individual survivors, with the implication often explicit, that the disease or death was related to the A-bomb. A 1972 survey of Nagasaki survivors within $2 \mathrm{~km}$ of the epicentre reported that $68 \%$ considered themselves to be in ill-health, especially from haematogenous disorders (Hospital Tribune, 1972).

Relationship of mortality to radiation dosage Mortality from disease has been shown to be higher among survivors with large radiation doses than among those with low doses or those not exposed (Jablon and Kato, 1971; Beebe, Kato, and Land, 1970). The increase appeared to be due primarily to higher mortality from leukaemia, significantly increased among those exposed to doses as low as $10-49 \mathrm{rad}$; and from other neoplasms, significantly increased among those exposed to doses of over 200 rad. Furthermore, the incidence of cancer other than leukaemia appears to be on the increase among those highly exposed (Jablon et al., 1971). Mortality from trauma has failed to differ significantly 
according to dose (Matsumoto, 1969; Jablon and Kato, 1971; Beebe et al., 1971).

Other conditions with radiation dose-response relationships

Radiation effects have been implicated in disease of the thyroid (Parker et al., 1973; Hollingsworth et al., 1963) and diseases of the eye (Nefzger, Miller, and Fujino, 1969 Miller, Fujino, and Nefzger, 1967). Short stature in adults has been more prevalent among those exposed to high radiation doses in childhood (Belsky and Blot, 1971). Mental retardation and small head circumference among those in utero at the time of the bombings have been more prevalent among the exposed. Small head circumferences have occurred with significantly increased frequency with radiation doses to the mother as low as 10-19 rad (Blot and Miller, 1973; Miller, 1956; Miller and Blot, 1972; Wood, Johnson, and Omori, 1967a; Wood et al., 1967b; Yamazaki, Wright, and Wright, 1954).

Morbidity and absenteeism in survivors of the atomic bombings

General morbidity in A-bomb survivors and absenteeism associated with it have been hard to quantify. Previous results have not been either definitive or consistent. Kato and Yoshitomi (1961) analysed illness episodes for the years 1958-59 among railway employees. The prevalence of illness (for which a doctor's treatment was received) of approximately 190 persons exposed within $2000 \mathrm{~m}$ of the hypocentre of the atomic bombs was higher than that of equal numbers of persons of similar age, sex, and job exposed outside $2000 \mathrm{~m}$ and those unexposed, but the differences were not statistically significant. Prolonged absenteeism (of six days or more) was greater among survivors than in the control population not in Hiroshima City during the bombings, but again not significantly so.

Komatsu et al (1963) found no differences in illness absences in 1959 and 1960 among 1221 men at the Mitsubishi shipyard in Nagasaki divided into groups of persons exposed within $2000 \mathrm{~m}$ matched by age and job with persons distantly exposed and unexposed.

\section{Material and methods}

Because the general belief that all A-bomb survivors were damaged conflicts with the equivocal results of previous absentee studies, the director and staff of the headquarters of the Atomic Bomb Casualty Commission (ABCC) in Hiroshima agreed to allow analysis of the agency's personnel records. Complete, detailed information on absentees was available for the entire Japanese staff of 428 persons, of whom 94 were officially designated survivors. Questions considered initially were whether survivors differed in work attendance from matched controls over a three-year period 23-26 years after the bombing, and whether these differences, if any, were related to radiation dosage received at the time of the bombing.

\section{Factors in study design}

Previous morbidity and absentee studies (Kato and Yoshitomi, 1961; Komatsu et al., 1963) had used much larger samples and recorded all illnesses diagnosed by physicians, but had not analysed information about short absences for health or other reasons. Their failure to demonstrate significant differences in types or lengths of illness according to A-bomb survivor status suggested a different approach. Information on all absences classified administratively for full-time employees was therefore obtained. The small data base made reduction of bias a principal requirement in the design of the study. Therefore, choice of cases and controls was made by a Japanese author (SI), but survivor status remained unknown to JWM and CRM who recorded absenteeism by administrative cause (not diagnosis) and coded results. Survivor status was also unknown to WJB, who performed all statistical tests, until exhaustive analyses established the probability that survivors differed from controls.

\section{Case control matching}

Bias in the selection process was reduced by including in the survivor group all employees who held an official

TABLE 1

Number of A-Bomb Handbook Holders and Controls by Sex, Age, Length of Service, and Pay Grade

\begin{tabular}{|c|c|c|c|c|c|c|c|c|c|c|}
\hline \multirow{2}{*}{ Sex } & \multirow{2}{*}{$\begin{array}{c}\text { Age } \\
(y r s)\end{array}$} & \multirow{2}{*}{$\begin{array}{c}\text { Handbook } \\
\text { status }\end{array}$} & \multicolumn{4}{|c|}{ Years of service } & \multicolumn{3}{|c|}{ Pay } & \multirow{2}{*}{ Total } \\
\hline & & & -9 & $10-14$ & $15-19$ & $20+$ & Lower & Middle & Upper & \\
\hline Male & $\begin{array}{l}-44 \\
45+ \\
-44 \\
45+\end{array}$ & $\begin{array}{l}\text { Survivor } \\
\text { Control } \\
\text { Survivor } \\
\text { Control } \\
\text { Survivor } \\
\text { Control } \\
\text { Survivor } \\
\text { Control }\end{array}$ & $\begin{array}{l}1 \\
4 \\
0 \\
0 \\
3 \\
4 \\
0 \\
1\end{array}$ & $\begin{array}{l}6 \\
2 \\
2 \\
2 \\
8 \\
9 \\
5 \\
2\end{array}$ & $\begin{array}{r}4 \\
5 \\
8 \\
6 \\
6 \\
6 \\
12 \\
8 \\
13\end{array}$ & $\begin{array}{r}8 \\
8 \\
13 \\
15 \\
11 \\
3 \\
11 \\
8\end{array}$ & $\begin{array}{r}1 \\
2 \\
0 \\
0 \\
10 \\
11 \\
3 \\
2\end{array}$ & $\begin{array}{l}15 \\
15 \\
14 \\
14 \\
18 \\
17 \\
17 \\
22\end{array}$ & $\begin{array}{l}3 \\
2 \\
9 \\
9 \\
0 \\
0 \\
4 \\
0\end{array}$ & $\begin{array}{l}19 \\
19 \\
23 \\
23 \\
28 \\
28 \\
24 \\
24\end{array}$ \\
\hline
\end{tabular}


handbook certifying that they had met survivor criteria. These 94 persons were then matched with 94 controls who were selected on the basis of sex, age, length of service, type of job, and pay. This detailed matching, with results shown in Table 1 and in the first two columns of Table 5, eliminated almost all possibilities for SI to choose more than one best fitting control. Where he had such choices, a random selection was made by JWM without reference to names. All four authors agreed that SI should make no inquiries into personal or medical histories of employees during his selection of controls. There can be no guarantee of elimination of all selection bias, but it was reassuring to learn later that SI had been unaware, when he selected them, that two control subjects considered themselves to be survivors, even though they were not handbook holders.

\section{Administrative comparability of cases and controls}

All handbook holders were selected without reference to their estimated radiation exposures at the time of the bombings. This information was studied after tests had established a difference between them and their controls. Under Japanese law, handbook holders were entitled to certain medical examinations and treatments, and to insurance benefits. This did not influence their leave opportunities or incentives at ABCC because all ABCC employees were required to have an annual medical examination that equalled or exceeded requirements under the A-bomb survivors' law. Similarly, sick leave and other employee benefits at ABCC generally exceeded those offered to survivors. None of the survivors in this study fell into the severely ill group with illnesses diagnosed as A-bomb dependent, which would have made him eligible for special benefits greater than those available to his matched control. Consequently, personnel regulations and administrative practices with respect to absenteeism should have applied equally to survivors and controls.

Types of absence information available

$A B C C$ records included notation of time away from work for all periods exceeding $30 \mathrm{~min}$, within the categories-annual, administrative, travel, special personal or obituary (death in family), without pay, sickness, and maternity. Annual and sickness leave accounted for $98 \%$ of all leave and $95 \%$ of all days lost. Both annual and sickness allowances usually were used for short periods of absence, averaging less than two days. For sickness absences lasting less than four days, a doctor's certificate was not required, so that diagnostic information was unavailable for the overwhelming majority of conditions for which sick leave was granted.

Inclusion of annual leave The decision to analyse annual leave as well as sick leave was made because the two types were correlated. When the 20 departments within ABCC were placed in rank order according to the average number of days of annual leave used for the fiscal year 1971, and compared with rank numbers for average number of days for sick leave in the same department, the Spearman rank order correlation test gave $r_{s}=0.725, P<0.01$. A reason for the correlation may be the custom at $\mathrm{ABCC}$ to use annual leave to meet a variety of short-term personal needs and to forgo long vacations.
Regulations governing leave-taking All persons included in the study were entitled to the same number of sick leave days per year (15) and annual leave days (24). However, a half-day of annual leave entitlement was lost for each five days of work less than 20 worked in any month. ABCC employees often took considerably less leave than available and almost all had accumulated the maximum permissible carryover of annual leave (48 days) and sick leave (60 days). A fiscal report for 1971 showed that the entire $\mathrm{ABCC}$ work force was on duty nearly $92 \%$ of all possible work days, although full use of annual leave alone would have reduced this to $91 \%$. All employees in this study received full pay for authorized leave of all types except 'leave-without-pay', a category that accounted for less than $0.2 \%$ of leave and less than $0.9 \%$ of days lost.

Details of classifying and coding absences The absence records for the period 1 July 1968 to 30 June 1971 of 94 survivors and 94 controls were determined, during which period all personnel policies had been uniform. The incidence and duration of absence were calculated for each employee according to the following rules. Each period of continuous absence was classified as a single episode, irrespective of its duration. Lengths of absence for each category of absence were recorded in whole days to the nearest whole hour and whole day-that is, less than 4 hour absences were counted as 0 days, 4-8 hour absences were counted as one day. An absence which had begun before 1 July 1968 was credited with days lost but the absence was not counted as an episode. Conversely episodes beginning on or before 30 June 1971 and extending to 1 July were counted as episodes, but days lost after 30 June 1971 were not counted. For absences beginning before a weekend or holiday and continuing after it, a single episode was counted when the employee was absent for the full day of Friday and Monday (or the day before and after a designated holiday).

Statistical methods To test for significant differences in absences and days lost because of annual leave or sickness Wilcoxon signed rank tests were employed. For each member of a matched pair, the total three year record of leave was noted. The difference in absences between handbook holder and control was then computed. These differences were tested for significance by the signed rank test. The effects upon leave-taking of the five factorssex, age, length of service, type of job, and pay-upon which the matching control was based were also tested by nonparametric methods (Wilcoxon or Kruskall-Wallis rank sum tests). For annual leave and days lost, variables following an approximate normal (Gaussian) distribution, a general linear (multiple regression) hypothesis model was employed, and tests for the effect of handbook status (adjusted simultaneously for sex, age, length of service, pay, and type of job) were performed.

\section{Results}

Most of the absences during the period 1968-71 were attributed to either annual or sick leave. Administrative leave, obituary leave, leave without pay, and travel leave when added together accounted 
for less than $2 \%$ of the total episodes of leave among the 188 men and women in this study, and less than $5 \%$ of total days lost. Twelve women were granted maternity leave during the three-year span, accounting for nearly $10 \%$ of the total days lost among women. There were no significant differences or consistent trends in results for these types of leave. In view of their small numbers and the impracticability of combining them in statistically valid ways with either annual or sick leave, they were omitted from further study.

Table 2 shows average numbers of episodes and days lost over the three-year period because of annual or sick leave according to A-bomb survivor status. Initially all subjects were considered together because a test was required to determine whether

TABLE 2

Average Number of Episodes and Days Lost DURING 1968-71 FROM ANNUAL AND SICK LEAVE ACCORDING to A-Bomb SURVIVOR STATUS

\begin{tabular}{lrr|cc}
\hline \multirow{2}{*}{$\begin{array}{c}\text { Handbook } \\
\text { status }\end{array}$} & \multicolumn{2}{c|}{ Episodes } & \multicolumn{2}{c}{ Days lost } \\
\cline { 2 - 5 } & Annual & Sick & Annual & Sick \\
\hline Survivor & 42.9 & $10 \cdot 4$ & $44 \cdot 5$ & $19 \cdot 0$ \\
Control & 39.0 & 8.4 & 39.9 & 12.0 \\
\hline
\end{tabular}

there was an overall difference between survivors and controls. The table shows there are higher averages of absenteeism among survivors. Table 3 lists the values of $z$, the normal approximation to the Wilcoxon statistic, used to test the significance of the differences between A-bomb handbook holders and controls as well as the number of pairs for which the controls had smaller or larger values than the A-bomb handbook holders. Ties were ignored. Handbook holders lost significantly more days for

TABLE 3

Matched Pair ANalysis of Differences in LEAVE-TAKING BeTWEen HaNDBOOK Holders aNd CONTROLS

\begin{tabular}{|c|c|c|c|}
\hline \multirow{2}{*}{ Variables } & \multirow{2}{*}{$\begin{array}{c}\text { Normal } \\
\text { approximation } \\
\text { to Wilcoxon } \\
\text { statistic } z\end{array}$} & \multicolumn{2}{|c|}{ No. of pairs where } \\
\hline & & $\begin{array}{c}\text { Control } \\
\text { took more } \\
\text { leave }\end{array}$ & $\begin{array}{c}\text { Survivor } \\
\text { took more } \\
\text { leave }\end{array}$ \\
\hline $\begin{array}{l}\text { Annual Leave } \\
\text { Episodes } \\
\text { Days lost }\end{array}$ & $\begin{array}{c}1.01 \\
2.20 \\
(\mathrm{P}<0.05)\end{array}$ & $\begin{array}{l}46 \\
35\end{array}$ & $\begin{array}{l}47 \\
58\end{array}$ \\
\hline $\begin{array}{c}\text { Sick Leave } \\
\text { Episodes } \\
\text { Days lost }\end{array}$ & $\begin{array}{c}0.85 \\
2.95 \\
(\mathrm{P}<0.01)\end{array}$ & $\begin{array}{l}42 \\
34\end{array}$ & $\begin{array}{l}50 \\
60\end{array}$ \\
\hline
\end{tabular}

TABLE 4

Average Number of Annual and Sick Leave Episodes and Days Lost during the Years 1968-71, for Survivors and Controls by Length of Service, SeX, Age, Pay, and Type of Job




TABLE 5

Significance of Nonparametric Tests on Effects of Length of Service, Sex, Age Category, Pay Scale, and Type of Job upon AnNual and Sick Leave Episodes and Days Lost in SuRvivors and CONTROLS

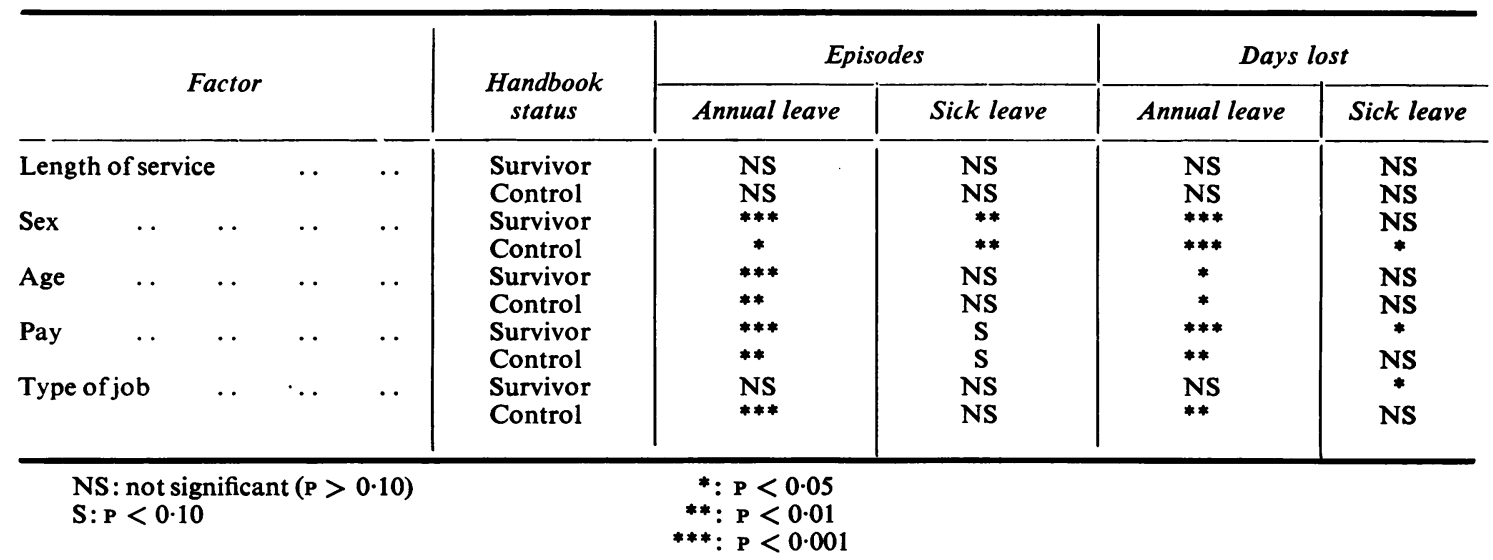

both annual leave $(\mathrm{P}<0.05)$ and sick leave $(\mathrm{P}<0.01)$ than their matched controls. Although the rank tests were not significant for episodes, handbook holders had higher positive rankings for both annual leave and sick leave.

Table 4 lists the three-year average rates of leavetaking according to sex, length of service, age, pay scale, and type of job. The averages show that the five variables account for differences of leave-taking in both groups. Table 5 gives the results of a series of Kruskall-Wallis rank sum tests performed within each of the survivor and control groups to test the significance of the five variables upon annual and sick leave episodes, and days lost. Sex, age category, and pay were all significant factors affecting annual leave days and episodes. Type of job was significantly related to annual leave days and episodes only among the controls. Only sex demonstrated a clearly significant effect upon sick leave days and episodes; women took more annual and sickness leave than men. Men of under 45 years took more annual leave than those who were older, and employees in the highest pay grade took less annual leave than others. Type of job had a significant effect upon both sickness and annual leave in the control group, and on sick leave in the survivor group. In the control group, manual workers had substantially fewer days of sickness and annual leave than employees in the other jobs. In the survivor group, manual workers lost substantially more days from sickness than any other occupational group, although they had no excess in the number of episodes of sick leave.

Because of the slight degree of mismatching between handbook holders and controls, an analysis of variance which examined the effect of survivor status adjusted for length of service, age, pay, sex, and type of job was conducted for annual leave episodes and days lost. An analysis of variance was not performed for sickness leave because of the pronounced skewness of the distribution of both sick leave episodes and days. Roughly two-thirds of the employees had less than 10 sick leave episodes, and less than 18 days lost due to sickness, but, for some, as many as 70 episodes and 76 days lost were recorded over the three-year period.

The analysis of variance is presented in Table 6 where the significance of each factor adjusted for all the other factors is listed. The results support the nonparametric tests in most respects, particularly the influence of A-bomb survivor status on days lost from annual leave.

It appeared probable that holders of A-bomb survivor handbooks had different patterns of absence from work than their matched controls, and a tendency to take more days off. Accordingly, it was possible to explore whether these patterns related to the dose of radiation received at the time of the bombings. Although the survivor and control status of the study groups are identified in the tables, this information was not known (except to author SI) when the analyses were made and the conclusion that one group had taken significantly more leave than the other was reached. Following that conclusion, SI investigated the histories of both survivors and controls with respect to several variables. For each survivor the dista nce at the time of the bombings from the hypocentre of the atomic bomb was listed as well as the estimated radiation dose in rads that he or she had received if this were known. Only 30 handbook holders were exposed within $2100 \mathrm{~m}$. 
TABLE 6

Analysis of Variance on the Effects of Handbook Status, Length of Service, Sex, Age, Pay Scale,

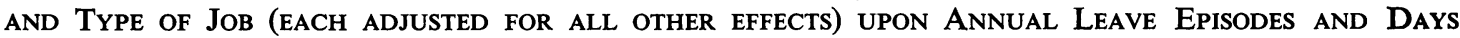

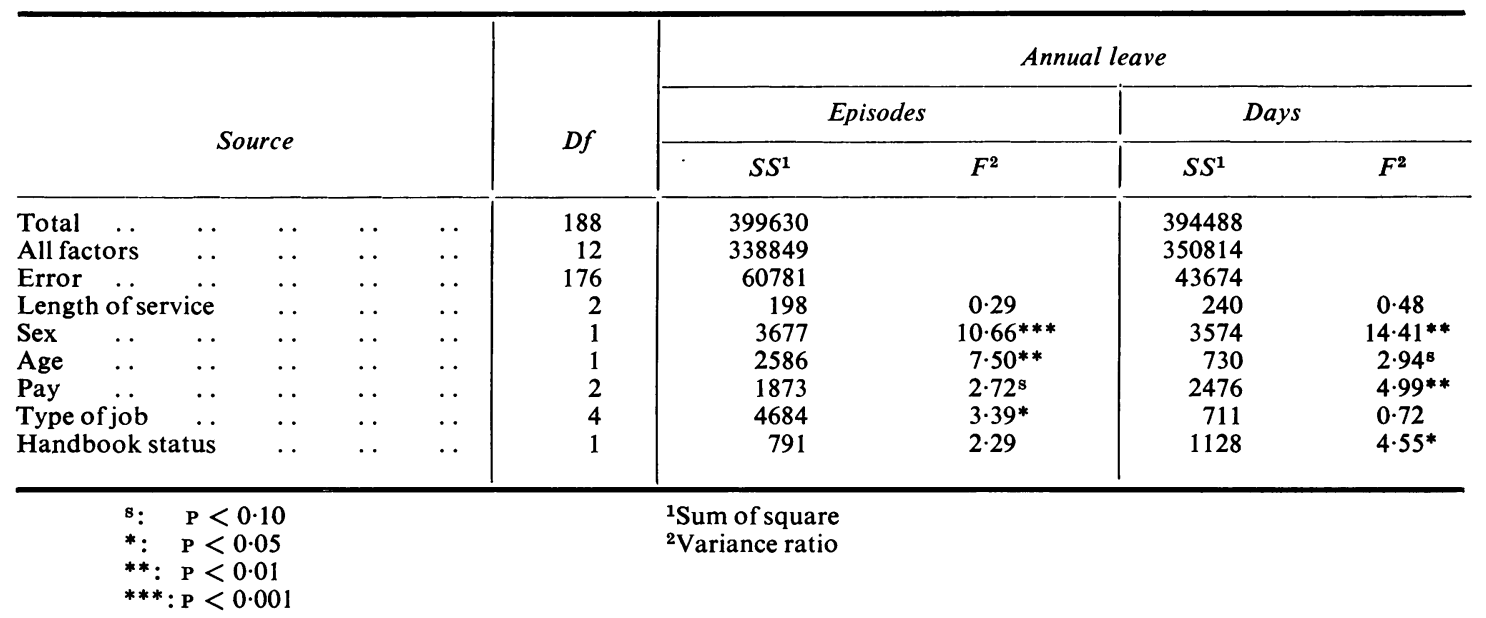

Although physical destruction from the atomic bomb extended to about $4000 \mathrm{~m}$, beyond $2100 \mathrm{~m}$ A-bomb radiation was less than $1.5 \mathrm{rad}$, and hence fell below average amounts since received from diagnostic radiology (Milton and Shohoji, 1968; Russell, 1971). Of the 30 exposed within $2100 \mathrm{~m}$, only seven were exposed within $1500 \mathrm{~m}$ where the estimated air dose was $32 \mathrm{rad}$. The 30 subjects who might have received more than $1.5 \mathrm{rad}$ were denoted the high dose group, recognizing this as a relative designation unrelated to the usual concept of a high dose. The remaining 64 were classified as the low dose group.

The composition of the high and low dose groups according to sex, age, type of job, and pay was fairly similar except for age. Of those in the high dose group $70 \%(21 / 30)$ were under the age of 45 , while only $41 \%(26 / 64)$ of those in the low dose group were under the age of 45 . Furthermore, there was a higher percentage of women in the high dose group. Both of these discrepancies in distribution would tend to increase leave-taking among the high dose group (Tables 4-6). Because of the age and sex differences between the high and low dose groups, an analysis of variance adjusting for sex and age as well as pay was used to test for differences in annual leave between the two groups. Because age was not significantly related to sick leave (Table 5), and because of the apparent abnormality of the sick leave observations, Wilcoxon rank-sum tests were used to test for differences in sick leave between the high and low dose groups. In both the analysis of

\section{TABLE 7}

Average Numbers of Episodes and Days Lost in 1968-71 for Handbook Holders According to Dose Group, Sex, AND AGE

\begin{tabular}{|c|c|c|c|c|c|c|c|c|}
\hline \multirow{2}{*}{\multicolumn{2}{|c|}{ Sex }} & \multirow{2}{*}{ Age } & \multirow{2}{*}{$\begin{array}{l}\text { Dose } \\
\text { group }\end{array}$} & \multirow{2}{*}{$\begin{array}{c}\text { Sample } \\
\text { size }\end{array}$} & \multicolumn{2}{|c|}{ Episodes } & \multicolumn{2}{|c|}{ Days lost } \\
\hline & & & & & Annual & Sick $^{1}$ & Annual & Sick ${ }^{1}$ \\
\hline $\begin{array}{l}\text { Male } . \\
\text { Female }\end{array}$ & $\ldots$ & $\begin{array}{l}-44 \\
45+ \\
-44 \\
45+\end{array}$ & $\begin{array}{l}\text { High } \\
\text { Low } \\
\text { High } \\
\text { Low } \\
\text { High } \\
\text { Low } \\
\text { High } \\
\text { Low }\end{array}$ & $\begin{array}{r}8 \\
11 \\
3 \\
20 \\
13 \\
15 \\
6 \\
18\end{array}$ & $\begin{array}{l}42 \cdot 3 \\
44 \cdot 5 \\
47 \cdot 9 \\
24 \cdot 8 \\
54 \cdot 9 \\
56 \cdot 3 \\
47 \cdot 6 \\
40 \cdot 8\end{array}$ & $\begin{array}{r}8.0(6.5) \\
4.5(5.0) \\
8.3(9.0) \\
6.8(4.0) \\
14.9(8.0) \\
15.4(12.0) \\
9.4(9.5) \\
11.4(10.0)\end{array}$ & $\begin{array}{l}41 \cdot 0 \\
43 \cdot 7 \\
37.0 \\
32 \cdot 7 \\
56 \cdot 2 \\
51 \cdot 7 \\
48 \cdot 3 \\
44 \cdot 9\end{array}$ & $\begin{array}{r}19.6(18.5) \\
6.5(4.0) \\
10.4(5.0) \\
25.3(11.0) \\
16.5(8.0) \\
18.7(17.0) \\
18.4(15.0) \\
22.9(17.5)\end{array}$ \\
\hline
\end{tabular}

${ }^{1}$ Numbers in parentheses are median values 
TABLE 8

Persons Exposed Within 1500 metres Listed with Estimated Doses of Radiation Where Known, AND LEAVE-TAKING EXPERIENCE

\begin{tabular}{|c|c|c|c|c|c|c|c|c|c|}
\hline \multirow[b]{2}{*}{ Subject } & \multirow{2}{*}{$\begin{array}{l}\text { Estimated } \\
\text { distance } \\
\text { from } \\
\text { hypocentre } \\
\text { (metres) }\end{array}$} & \multirow[b]{2}{*}{ Age } & \multirow[b]{2}{*}{ Sex } & \multirow[b]{2}{*}{ Shielding } & \multirow{2}{*}{$\begin{array}{c}\text { Estimated } \\
\text { dose } \\
(\text { rad })\end{array}$} & \multicolumn{4}{|c|}{ 3-year leave totals } \\
\hline & & & & & & $\begin{array}{r}A \\
\text { Episodes }\end{array}$ & $\begin{array}{l}\text { al } \\
\text { Days } \\
\text { lost }\end{array}$ & Episodes & $\begin{array}{l}\text { Days } \\
\text { lost }\end{array}$ \\
\hline $\begin{array}{l}121 \\
391 \\
162 \\
512 \\
631 \\
\\
201 \\
811\end{array}$ & $\begin{array}{r}700 \\
800 \\
900 \\
1000 \\
1200 \\
\\
1300 \\
1300\end{array}$ & $\begin{array}{l}47 \\
41 \\
42 \\
48 \\
\\
39 \\
\\
40 \\
30\end{array}$ & $\begin{array}{l}M \\
F \\
M \\
F \\
M \\
F \\
F\end{array}$ & $\begin{array}{l}\text { in street car } \\
\text { unknown } \\
\text { inside concrete } \\
\text { building } \\
\text { inside wooden } \\
\text { building }\end{array}$ & $\begin{array}{c}128 \\
\text { unknown } \\
\text { unknown } \\
\text { unknown } \\
18 \\
71 \\
17\end{array}$ & $\begin{array}{l}67 \\
74 \\
27 \\
\\
58 \\
\\
63 \\
67 \\
14\end{array}$ & $\begin{array}{l}46 \\
65 \\
42 \\
\\
47 \\
\\
49 \\
61 \\
35\end{array}$ & $\begin{array}{l}03 \\
51 \\
13 \\
\\
20 \\
\\
02 \\
08 \\
00\end{array}$ & $\begin{array}{l}05 \\
49 \\
39 \\
\\
23 \\
\\
02 \\
09 \\
00\end{array}$ \\
\hline & M & & & m Table 2) & .. & $\begin{array}{l}52 \cdot 8 \\
42 \cdot 9\end{array}$ & $\begin{array}{l}49 \cdot 2 \\
44 \cdot 5\end{array}$ & $\begin{array}{l}13 \cdot 8 \\
10 \cdot 4\end{array}$ & $\begin{array}{l}18 \cdot 0 \\
19 \cdot 0\end{array}$ \\
\hline
\end{tabular}

variance and Wilcoxon tests, dose grouping was not significantly related to leave-taking.* The mean rates for annual and sick leave episodes and days lost, as well as median values for sick leave, are given by sex and age for the high and low dose groups in Table 7. The sex and age specific differences between high and low dose means or medians are occasionally large but not consistent in direction.

The annual and sick leave of the seven persons exposed within $1500 \mathrm{~m}$ from the hypocentre are listed in Table 8, with details, as known, of their exposure histories. Two of the seven received more than 50 rad from the bomb. Both took less than average sick leave (Table 2) but more than average annual leave compared with other handbook holders. The average number of annual leave episodes and days lost and sick leave episodes of the seven individuals exceeded the averages for all handbook holders, however the excesses accounted for not more than a small fraction of the excess of all handbook holders over controls. The average number of days lost due to sick leave was less among the seven than the average of all handbook holders.

\section{Discussion}

At $\mathrm{ABCC}$ headquarters in Hiroshima, Japan, the group of 94 employees officially designated as A-bomb survivors had greater absenteeism during the three years $1968-71,23$ to 26 years after the

*For annual leave, with type 1 error $\alpha=0.05$, type II error $\beta=0 \cdot 10$, the analysis of variance was able to detect one-sided differences between the high and low dose three year annual leave means of approximately 12.6 for episodes and 9.9 for days. explosion, compared with a group of 94 carefully matched controls. The significantly greater numbers of days lost among survivors for both annual and sick leave, however, could not be shown to be related to the amount of radiation dosage received from the bomb. This result raises many questions, of which only a few can be answered.

The study took into account factors that were thought to influence absenteeism. However, sources of possible bias existed that had not been dealt with specifically in the design. Komatsu et al. (1963) found that unmarried survivors had excess sickness absences. Matching for marital status was not a requirement in our selection procedure for controls. However, among the 52 pairs of women, the marital status (married $v s$ unmarried) of each partner was the same in all cases but one. Among the 42 pairs of men, an unmarried survivor was paired with a married control in five cases. In three of these pairs, handbook holders had more annual and sick leave days lost than their controls. In the other two pairs they had less. The five unmarried male handbook holders had slightly greater mean excess annual leave episodes and days lost than the overall excess among male survivors, and slightly lower mean excess sick leave rates.

Komatsu et al. (1963) also noted that persons who had long journeys between home and work, whether on foot or in vehicles, had excess sickness absence rates. To test for possible bias related to commuting distances for each member of the study for 1971 were recorded: the distance in $\mathrm{km}$ between home and $\mathrm{ABCC}$, the usual means of commuter travel (private car, public transport, bicycle, or foot), and the estimated daily travel time to work. Com- 
parison of survivor and control pairs showed that the distance was greater for survivors than for controls in 39 pairs, less in 43 , equal in 12 . Mean survivor distance was $8 \cdot 1 \mathrm{~km}$, control $10 \cdot 2$. Mean survivor time was $42.9 \mathrm{~min}$, control 48.8 . There were no significant differences in methods of commuter travel between survivors and controls. Any bias from excess commuting should have increased leave-taking among controls.

Another possible source of bias might have been misclassification of survivors. SI purposely avoided investigation of personal histories of handbook holders and controls while he was selecting matching pairs. After completing data collection and analysis, the authors considered factors related to survivor status. The criteria for issuing Atomic Bomb Survivor Handbooks are somewhat complex and have been changed several times since 1945 (Japan Law no. 41, 1957). Among the 94 ABCC employees with handbooks, 72 were directly exposed within $4 \mathrm{~km}$ of the hypocentre of the explosion. Twenty-two were not directly exposed-that is, they were more than $4 \mathrm{~km}$ from the centre, but entered the city within two weeks after the bomb, most (16) entering within three days. These late entrants were entitled to handbooks identifying them as A-bomb survivors, yet it is generally felt that the Hiroshima bomb produced negligible amounts of residual radiation (Arakawa, 1962). Furthermore, of the 72 directly exposed, only 30 were exposed within $2 \mathrm{~km}$ where the estimated air dose was $1.5 \mathrm{rad}$ (Milton and Shohoji, 1968).

Handbooks were issued only to persons who followed specific procedures that included presenting evidence from witnesses and filing claims within time schedules. Periodic changes in the law resulted in occasional inconsistencies. In our study group, two women may have been incorrectly classified as controls. One who was in the city at the time of the bombings had not exchanged her handbook when she was supposed to under a change in law, and was unable to re-establish her rights at a later date. The other believed she should have qualified for a handbook under the late entrant provision of the 1957 law, but could not find witnesses at that time. Comparison of these women's records with their matched handbook holders showed that each had taken more annual and sick leave days than their respective 'twin'. If both pairs were dropped, differences between handbook holders and controls would increase.

If excess sick leave had frequently been an important indicator of radiation damage, one could guess that employment survivorship factors might have eliminated some subjects whose illness rates interfered chronically and seriously with their performance. Irrespective of selection factors among subjects who received significant radiation, there was no scientifically supportable way to attribute excess absenteeism in the survivor group as a whole to direct tissue damage from radiation at the time of the bombings, because the overwhelming majority had received doses comparable with average amounts from subsequent diagnostic radiation.

Having ruled out a serious effect of biases, the explanation of our results is behavioural. Matsumoto's (1969) report would make this seem logical, but our data permitted only limited exploration of this hypothesis, through inferences that might be drawn from comparison of our results with other studies of absenteeism. The investigation of survivor and control attitudes was not possible. The importance of behavioural influences on absence rates is well known. Taylor, Pocock, and Sergean (1972) noted their own and other work on the subject in studies of shift workers, and suggested that sickness absence be regarded as a 'type of withdrawal from work to be looked at in conjunction with other forms of absence'. These authors also referred to the inverse relationship between absenteeism and increasing levels of skill. Froggatt's comprehensive studies of short-term absence from industiy (Froggatt, 1970a, 1970b, 1970c) showed that: the causes of short absences could not be classified satisfactorily, especially those of medical absences; one-day absences were correlated positively with lateness to work and negatively with age, but were not correlated with diagnosed illness; two-day absences were correlated with both one-day absences and certified sickness. Although he did not discuss the influence of sex on short absences, his Table 11 (Froggatt, 1970a) showed for each of seven years there were higher mean rates for both one-day and two-day absences among 27 women than among 71 men 'employed for seven consecutive years'. This was consistent with earlier reports that women had more absences than men (Gafafer, 1943; Baetjer, 1947; Thomson, 1972; Wilder, 1972).

Inclusion in our study of annual as well as sick leave absences seems reasonable in the light of the demonstrated correlation within $\mathrm{ABCC}$ for the two types of leave. Since annual leave episodes at ABCC had a mean length of only 1.03 days, they may have been similar to the short absences, especially one-day absences, studied by Froggatt. Their significant negative correlation with age was consistent with his findings, suggesting a behavioural component in annual leave-taking practices. Significantly greater use of annual leave entitlements by women than men at $\mathrm{ABCC}$ would also fit a behavioural hypothesis, as would significantly less annual leave-taking by employees in the upper pay brackets or supervisory positions (Tables 4,5 , and 6 ).

If one accepts that use of annual leave at $A B C C$ reflected behavioural factors, A-bomb survivorship could be viewed as one of the smaller determinants. 
The influences of sex, age, and pay scale were each greater. It was of interest that survivors in skilled and supervisory jobs, where behavioural factors have been invoked to explain lowered absence rates, took slightly less mean annual leave than controls.

Sick leave at ABCC was also taken largely as short spells of absence, with an overall mean length of 1.66 days lost per episode. Table 4 indicates that mean values for sick leave and annual leave by survivor status within the various subgroups are generally parallel. Table 5 shows that nonparametric tests were generally confirmatory of trends indicated by differences in group means. Results seem consistent with a behavioural hypothesis.

Our conclusion was that the fact of being designated as survivors of the atomic bombing of Hiroshima probably influenced them as a group in the direction of taking somewhat more than the expected number of days of both annual and sick leave 23 to 26 years later. This effect was not radiation dose dependent. Although the excess of absenteeism for handbook holders was not very great, and was less consistent than differences attributable to other variables, it was of theoretical interest in the light of Froggatt's (1970c) comment that the 'proclivity to discontinuous work may be an inherent and not an adaptive attribute which can be modified but not radically altered by the environment'.

The authors wish to acknowledge the kind assistance of the director and staff of the Atomic Bomb Casualty Commission, Hiroshima, Japan, for permitting access to their personnel absenteeism records.

\section{References}

Arakawa, E. T. (1962). Residual radiation in Hiroshima and Nagasaki. Atomic Bomb Casualty Commission Technical Report 2-62, Hiroshima.

Baetjer, A. M. (1947). Women in Industry, chap. 7. Saunders, Philadelphia.

Beebe, G. W., Kato, H., and Land, C. E. (1970). Mortality and radiation dose, October 1950-September 1966. Atomic Bomb Casualty Commission Technical Report 11-70, Hiroshima.

Belsky, J. L. and Blot, W. J. (1971). Adult stature in relation to childhood exposure to the atomic bombs of Hiroshima and Nagasaki. Atomic Bomb Casualty Commission Technical Report 35-71, Hiroshima.

Blot, W. J. and Miller, R. W. (1973). Mental retardation following in utero exposure to the atomic bombs of Hiroshima and Nagasaki. Radiology, 106, 617-619.

Froggatt, P. (1970a). Short term absences from industry. I. Literature, definitions, data and the effect of age and length of service. British Journal of Industrial Medicine, 27, 199-210.

(1970b). Short term absences from industry. II. Temporal variation and inter-association with other recorded factors. British Journal of Industrial Medicine, 27, 211-224. (1970c). Short term absences from industry. III. The inference of 'proneness' and a search for causes. British Journal of Industrial Medicine, 27, 297-312.

Gafafer, W. M. (1943). Sickness absenteeism among male and female industrial workers, 1933-42, inclusive. Public Health Reports, 58, 1250-1254.

Hollingsworth, D. R., Hamilton, H. B., Tamagaki, H., and Beebe, G. W. (1963). Thyroid disease: A study in Hiroshima, Japan. Medicine, 42, 47-71.

Hospital Tribune (1972). New York, Monday 18 September.

Jablon, S. and Kato, H. (1971). Mortality among Abomb survivors, 1950-1970. Atomic Bomb Casualty Commission Technical Report 10-71, Hiroshima.

_- Tachikawa, K., Belsky, J., and Steer, A. (1971). Cancer in Japanese exposed as children to atomic bombs. Lancet, 1, 927-931.

Japan (Tokyo). Law concerning medical treatment of A-bomb survivors (Law No. 41, 31 March 1957); and enforcement ordinance (Government Ordinance No. 75, 25 April 1957); and amendments of 1 August 1960, 31 March 1962, 1 October 1965, 1 April 1972.

Komatsu, T., Hashimoto, T., Omishi, S., and Fujisawa, H. (1963). Illness episodes and A-bomb exposure: A study of absenteeism among Nagasaki Mitsubishi shipyard workers. Atomic Bomb Casualty Commission Technical Report 2-63, Hiroshima.

Kato, H., and Yoshitomi, M. (1961). Illness episodes among employees of Hiroshima railway division, pilot study: 1. Morbidity; 2. Absenteeism. Atomic Bomb Casualty Commission Department of Epidemiology and Hiroshima Branch Laboratory National Institute of Health and Hiroshima Railway Hospital, Atomic Bomb Casualty Commission Technical Report 18-61, Hiroshima.

Matsumoto, Y. S. (1969). Social impact on atomic bomb survivors, Hiroshima and Nagasaki. Atomic Bomb Casualty Commission Technical Report 12-69, Hiroshima.

Miller, R. W. (1956). Delayed effects occurring within first decade after exposure of young individuals to the Hiroshima atomic bomb. Pediatrics, 18, 1-18.

- and Blot, W. J. (1972). Small head size following in utero exposure to atomic radiation. Lancet, 2, 784-787.

- , Fujino, T., and Nefzger, M. D. (1967). Lens findings in atomic bomb survivors. A review of major ophthalmic surveys at the Atomic Bomb Casualty Commission 1949-1962. Archives of Ophthalmology, 78, 697-704.

Milton, R. C. and Shohoji, T. (1968). Tentative 1965 radiation dose estimation for atomic bomb survivors, Hiroshima and Nagasaki. Atomic Bomb Casualty Commission Technical Report 1-68, Hiroshima.

Nefzger, M. D., Miller, R. J., and Fujino, T. (1969). Eye findings in atomic bomb survivors of Hiroshima and Nagasaki, 1963-1964. American Journal of Epidemiology, 89, 129-138.

Parker, L., Belsky, J., Mandai, T., Blot, W., and Kawate, R. (1973). Serum thyrotropin level and goiter in relation to childhood exposure to atomic radiation. Journal of Clinical Endocrinology and Metabolism, 37, 797-804.

Russell, W. J. (1971). Medical $x$-ray exposure among Hiroshima and Nagasaki A-bomb survivors. Nippon Acta Radiologica, 30, 12-34. 
Taylor, P. J., Pocock, S. J., and Sergean, R. (1972). Absenteeism of shift and day workers. A study of six types of shift system in 29 organizations. British Journal of Industrial Medicine, 29, 208-213.

Thomson, D. (1972). Sickness absence in the civil service. Proceedings of the Royal Society of Medicine, 65, 572-577.

Wilder, C. S. (1972). Time lost from work among the currently employed population. United States 1968. Vital and Health Statistics, Series 10. No. 71. U.S. Department of Health, Education and Welfare, Publication No. (HSM) 72-1053. Washington, D.C. Wood, J. W., Johnson, K. G., and Omori, Y. (1967a). In utero exposure to the Hiroshima atomic bombfollow up at 20 years. Pediatrics, 39, 385-392.
- - - Kawamoto, S., and Keehn, R. J. (1967b). Mental retardation in children exposed in utero to the atomic bombs in Hiroshima and Nagasaki, American Journal of Public Health, 57, 1381-1390.

Yamazaki, J. N., Wright, S. W., and Wright, P. M. (1954). Outcome of pregnancy in women exposed to the atomic bomb in Nagasaki. American Journal of Diseases of Children, 87, 448-463.

Received for publication 9 April 1974.

Accepted for publication 20 January 1975 